\title{
Crime against Humanity \\ - Uncovering Two Decades of Corruption in the FDA Regarding DMD Treatment
}

\author{
Peter K. Law \\ Cell Therapy Institute, Wuhan, China \\ Email: peter@celltherapy.com
}

How to cite this paper: Law, P.K. (2017) Crime against Humanity. Open Journal of Regenerative Medicine, 6, 35-45. https://doi.org/10.4236/ojrm.2017.64004

Received: September 21, 2017

Accepted: October 23, 2017

Published: October 26, 2017

Copyright $\odot 2017$ by author and Scientific Research Publishing Inc. This work is licensed under the Creative Commons Attribution International License (CC BY 4.0).

http://creativecommons.org/licenses/by/4.0/

\begin{abstract}
The world needs to know the facts as to how the FDA "protects" the public health by assuring the safety, effectiveness, and security of human drugs and biological products for human use. Recent uproar has surfaced over the FDA's approval process on the unproven Duchenne Muscular Dystrophy (DMD) drug, Exondys 51 (Sarepta Therapeutics, Cambridge, MA, USA), but what many people do not know are the unlawful events that occurred nearly two decades ago on a proven and promising treatment for DMD.
\end{abstract}

\section{Keywords}

FDA Corruption, DMD, Duchenne Muscular Dystrophy, Exondys 51, Myoblast Transfer Therapy, Peter K. Law, Disqualification

\section{What Are DMD and Myoblasts?}

Fatal and debilitating, DMD is a rare childhood genetic disease confining boys into wheelchairs by age 12 and often suffocating them by age 20 . The genetic defect manifests in the absence of a membrane structural protein called dystrophin, without which, the muscle fibers break and die as the bones elongate beginning at age 5. The anti-gravitational muscles usually lose $50 \%$ of muscle fibers and strength by age 9 and $80 \%$ by age 12. Muscle fiber degeneration also strikes the neck, the back, the girdles and the upper limbs, deforming and weakening the children to the point that they cannot breathe. A logical treatment to replenish the dead muscle fibers with live ones and genetically repair the degenerating ones is called Myoblast Transfer Therapy (MTT).

Genetically normal myoblasts are obtained in tens of billions from the primary culture of satellite cells isolated from muscle biopsy of pathogen-free healthy male donor. Myoblasts are differentiated cells destined to become muscles. 
Mammalian evolution over 160 million years witnesses their unique ability to fuse during muscle development and regeneration. Implanted myoblasts naturally fuse among themselves to form genetically normal muscle fibers to replenish dead fibers. They also fuse with dystrophic muscle fibers, inserting their nuclei that carry the normal genome to produce genetic complementation repair. As such, MTT is a somatic cell therapy and a gene therapy, or more correctly, a genome therapy with nuclei transfer.

\section{Development of Myoblast Transfer Therapy}

First published in Lancet on July 14, 1990, MTT is the world's first human gene therapy to have replenished dystrophin, a structural protein not produced in DMD muscles [1]. That was the dawn of Regenerative Medicine in the field of somatic cell therapy. If replenishing dystrophin is all that it takes to cure DMD and to be granted FDA Biologic License Approval (BLA), my team had achieved that in the year 1990, if not, then in the years ensuing. We even demonstrated that dystrophin persisted in the same muscle at six years after MTT [2]. The work came after 15 years of basic research supported by 11 years of top-priority NIH (National Institutes of Health) grants.

The organization that I founded, Cell Therapy Research Foundation (CTRF), had requested granting of a Treatment IND (Investigational New Drug) in 1998, but it was turned down. FDA admitted that functional data had demonstrated efficacy, but had question about histology. It is not difficult to see histologic efficacy in our publications dated before November 1998 [1]-[11]. In reality, functional improvement in muscle contraction should be the primary end point for these clinical trials and not dystrophin production alone.

I pioneered and developed MTT to treat DMD, unto fast-track Phase III clinical trials with approval to charge for 5 consecutive years following progress reviews by the Center for Biologics Evaluation and Research (CBER). At the height of my career, patients from 20 countries came to USA to seek treatment in the non-profit CTRF that I founded and chaired. For political and financial reasons that were not obvious at the time, my research was abruptly put on hold by the FDA and I was forced to abandon my mission. By disqualifying me as an investigator the FDA forced me out of the USA where I spent 29 years of my academic career beginning as an Assistant Professor then Full Professor and Chairman of the non-profit CTRF. I had no alternative but to leave the USA in order to continue with my mission in life, knowing full well that no one else in the world came close to my knowledge on the technology.

The following video segment showcases the physical improvement of dystrophy patients after MTT as documented by representative patients (24 cases), parents and news media:

http://www.youtube.com/watch?v=mU3-_IQ15x4 (English)

https://v.qq.com/x/page/n0522dwcoi5.html (Chinese)

The benefits versus risks ratio of MTT is outstanding. Many of the DMD boys 
treated only once by my team 20 years ago are currently alive in their 30 's and 40 's. Unfortunately, within these decades, millions of DMD patients lost the opportunity to be treated by MTT due to the actions or inactions of the FDA.

The benefits of MTT can only be obtained with 50 billion myoblasts implanted into 82 muscle groups of each DMD boy. My team is the only one in the world which is capable of producing such effects using the innovative techniques that we invented and developed over the years [3] [4].

\section{FDA Regulatory History of MTT and CTRF}

FDA began regulating cell therapies in the year 1993. From 1994 to 1999, FDA allowed CTRF to charge upon satisfactory annual review of the progress of the Phase II and Phase III clinical trials on DMD, Becker muscular dystrophy (BMD) and Limb-girdle muscular dystrophy (LGMD). By November 1998, the BB-IND 5108 trials were allowed multicenter Phase III Fast Track development. The Public Health Ministry of the Russian Federation, the Hungarian National Insurance Fund Administration, the German Health Insurance system, and the Brazilian government were paying CTRF in Memphis, Tennessee US\$150,000for a MTT for each of their DMD citizens. To meet American demand, many foreign patients had to be turned away because of the limited number of subjects allowed by the FDA in the studies.

My team continued to publish quality controls of myoblast manufacture, including cell identity, purity, quantity, viability, potency, sterility, mycoplasma and endotoxins in dose-escalation, natural history and randomized, doubleblind studies. Much of what my team published found their way into the April 1, 1997 revision of the FDA Code of Federal Regulation (CFR) 21.

Instead of granting BLA to BB-IND 5108, "Cultured Allogeneic Myoblasts, and Cyclosporin (Sandoz)", FDA initiated a guided investigation of CTRF in 1999, stopped all its clinical trials, physically destroyed its storage of myoblasts without testing, and capriciously initiated disqualifying me as an investigator. The destroyed myoblasts represented years of painstaking R\&D and financial investment. They belonged to the same batches of cells that kept patients alive as of today.

In the lengthy, make-believe " 483 "s that described logistic rather than scientific deficiencies, there was not a statement describing death or permanent severe adverse reaction of any trial subject. There was no statement describing dishonesty or forgery. Our response to the " 483 "s were simply ignored. CTRF went bankrupt after FDA would not allow the study to move forward.

\section{The Controversy}

In 2016, US FDA approved Exondys 51 developed by Sarepta Therapeutics as the first DMD drug. They approved Exondys 51 on fast track, priority review, and orphan drug designation. Accelerated approval made this drug available to patients based on initial data. The aftermath was not pleasant. 
The FDA News Release on September 19, 2016 documented that, "A clinical benefit of Exondys 51, including improved motor function, has not been established" and that, "The most common side effects reported by participants taking Exondys 51 in the clinical trials were balance disorder and vomiting" (Attachment 1) [12]. The Associated Press on the same day called Exondys 51 "the largely unproven medication." [13]

In the following months, media outlets and reputable individuals lambasted the FDA's egregious decision making [14] [15] [16] [17] [18]. This controversy was not only evident in the public eye, but also internally within the FDA itself [19] [20] [21]. Prior to his retirement, John Jenkins, the Director of Office of New Drugs (OND), presented the lessons learned from the Exondys 51 catastrophe at a NORD summit meeting. Furthermore, the FDA's refusal to disclose records sparked a federal lawsuit from a top American science journalist and New York University professor, Charles Seife [22] [23].

It is clear the FDA exercised a different standard when approving Exondys 51, but did their actions stem from incompetence or corruption? Further yet, could a contrary situation have occurred where a viable treatment option was not only declined, but maliciously destroyed? Could these dishonest and unlawful practices date back to nearly two decades ago? Why was MTT in BB-IND 5108 subjected to a hostile and unprecedented standard towards the end? Tables 1-3

Table 1. Efficacy comparison.

\begin{tabular}{lc}
\multicolumn{1}{c}{ MTT } & Exondys 51 \\
\hline $\begin{array}{l}\text { 1. } 100 \% \text { dystrophin production } \\
\text { 2. } 70 \% \text { muscle fiber increase and histology improved } \\
\text { 3. 123\% strength increase in 18 months }\end{array}$ & None \\
4. $48.7 \%$ decrease in serum CPK in 1 year & None \\
5. 19\% increase in breathing capacity & None \\
6. Physical capacity improved & None \\
7. Life prolonged & None \\
8. For DMD, BMD and other MDs & Fone \\
\hline
\end{tabular}

Table 2. Safety comparison.

\begin{tabular}{ll}
\hline MTT & Exondys 51 \\
\hline 280 cases published & 8 cases +4 untreated controls, unpublished \\
$100 \%$ safe & Balance disorder/vomiting \\
\hline
\end{tabular}

Table 3. Logistics comparison.

\begin{tabular}{cc}
\hline MTT & Exondys $\mathbf{5 1}$ \\
\hline One time intramuscular injection & Daily intravenous injection \\
Lifelong benefits & No clinical benefit \\
US\$150,000- total, FDA approved & US\$300,000- and above per year \\
\hline
\end{tabular}


show a comparison of proven and published results between Exondys 51 and MTT.

In their teachings, Harvard Law School used a 1997 study on FDA misdirection (Attachment 2) [24]. The article describes how large drug companies tear down innovative inventors through the FDA. These practices were unbeknownst to me at the beginning of my career. As my work and career ascended, I became a victim of that abusive power.

I have been character-assassinated by the FDA disqualification letter posted even today on the internet since year 2002. Many accusations in the letter are untrue. A team of outstanding Tennessee licensed physicians and professors volunteered to guard the safety of the test subjects. Despite repeated emphases of my placing the safety and welfare of subjects enrolled in the studies at risk, not a statement existed to describe death or permanent severe adverse reaction of a trial subject. My trial design and our clinical practices had protected $100 \%$ of these DMD subjects from death within the two years of each trial period and of many trials lasting over 26 years. More than $99 \%$ of the FDA approved trials did not match that. We subjected our subjects to calculated risks, like any other clinical trial teams, so that these DMD patients might live longer and have better quality of life.

The FDA disqualification letter has deprived me of $99 \%$ of funding opportunities and its intent is to end my career as a medical scientist. In my busy schedule of developing heart muscle regeneration that would help the DMD boys in time, I underestimated the significance of the disqualification hearing and entrusted it to the CTRF Vice President of Regulatory Affairs who failed to appear and represent me.

In 1999, MTT was the only FDA approved clinical trial program for muscular dystrophies. CTRF had difficulty in turning MD patients away because of the limited number of subjects allowed by the FDA to participate in the trials. CTRF quickly equipped 10 centers for Phase III trial in early 1999, only to discover soon after that BB-IND 5108 was put on hold until its bankruptcy in 2003.

There are MTT patients living in their thirties and forties whose uncles died at age 18 without MTT. They are living proof of the real benefit of MTT. The personal satisfaction I have from their grateful parents is what kept me forging on against all odds.

\section{The Rise, Fall and Return of MTT}

My pioneering studies, published in peer-reviewed journals, have been featured on world news media including CNN, BBC, CBC, NBC, USA Today, New York Times and Wall Street Journal. I received numerous grants/awards and I have been published in many internationally reputable journals such as Science, Nature, Lancet, Circulation and books [1]-[11].

In 1978 when human somatic cell therapy was not even contemplated, I had my colleague taking a muscle biopsy from my left thigh for me to develop the 
techniques of human myoblast culture. The sacrifice that my team went through was truly beyond the call of duty.

Many physicians donated their expertise, time, and efforts to BB-IND 5108.Tremendous time and efforts were put into assembling, training, and aligning the various members of the CTRF team. There was and still is no better team on earth than the CTRF team in MTT. Its contribution says for itself. However, officers of the FDA Compliance Office were like butchers on the block, heartlessly destroying all those resources. It is heartbreaking to see such immense destruction of the delicate and benevolent dream of saving children.

Despite these events, I was determined to persist and accomplish the lifelong dream I began in 1972. Whereas most people at this stage of their life are enjoying retirement, I chose to battle on knowing that MTT could save hundreds of millions from suffering as they have in the last 20 years since the FDA attempted to end my work. As a scientist, I felt that it was my responsibility to see this technology through. I had successful research results not only in muscular dystrophy, but also in treating ischemic cardiomyopathy, a consequence of coronary artery disease [25]-[30]. MTT could be further developed to treat cancer, Type II diabetes and anti-aging effects, yet the opportunity to explore these fields was obliterated.

In 2009, Chinese officials caught wind of my work and after understanding the science behind MTT, they invited me to attend the $60^{\text {th }}$ anniversary of the founding of the People's Republic of China where I met with the past and present Chairmen, Prime Ministers and higher officials. They awarded me with the highest municipal reward of the " 3551 Talents Program" and later on the highest national reward, "Thousand Talents Program". China saw the potential of my technology and seized the opportunity to become the world leader in treating muscular dystrophy, cancer, heart failure, Type II diabetes and aging through MTT. I established Cell Therapy Institute (CTI) in Wuhan, China where we continued to have breakthroughs by successfully treating cancer tumors, Type II diabetes, heart failure and muscular dystrophy using MTT in human trials [31] [32] [33]. MTT technology is on the verge of a worldwide boom and CTI is now accepting foreign patients for the treatment of DMD.

\section{Closing Remarks}

As an accomplished scientist who has spent 46 years in muscle regeneration, I do not believe any drug of biochemical nature can replenish the estimated 50\% muscle fiber loss when DMD boys go into wheelchairs and the estimated $80 \%$ loss when they suffocate. Dystrophin is a large structural protein and its gene cannot be accommodated less integrated effectively with any viral vector. Dystrophin expression using viral vector is conceptually incorrect. Utrophin is not dystrophin and has difficulty fitting in its precise position and function. Even if a new drug can regenerate muscle fibers, meaning that a biochemical can generate live cells, the new cells will still carry the dystrophic gene, and the regeneration 
of these cells will become abortive. Using a drug to treat DMD is conceptually incorrect.

Pertaining to MTT, there are patients who were treated 20 years ago that are still alive today to give their testimonial on this treatment. It was clinically demonstrated that there was significant improvement in safety and effectiveness, so why was MTT not granted priority review in 1998? Why MTT was not allowed to proceed with its Phase III fast track trial? And most of all, why disqualify its pioneering scientist whose program had killed no MD subject? What drastic change has occurred that prompted the FDA to put the BB-IND 5108 on hold perpetually? Be it the case as with some failing drugs or biologics, the FDA usually does not disqualify their inventors or chief scientists.

What is capricious is the drumming up of false evidence in the " 483 "s and disqualification letter to derail BB-IND 5108, ending my highly successful scientific career in the USA and depriving me of financial support for my work worldwide even as of today. All I did was to develop treatments for hereditary, fatal and debilitating diseases with no known cure. My teams did this without taking the life of any patient or causing any permanent adverse reaction.

The events of the last 20 years have demonstrated how easily FDA's decision making can be manipulated into non-scientific, unjust and possibly illegal practices. Behind the pitiful faces of children dying with DMD, behind the great American spirit of saving the world hides a sea of greed for power and money. Left unchanged, the deeply entrenched legalized corruption system perpetuates thereby the ill dies without medicine and dies with approved medicine. It is a crime that members of society in a position of entrusted power lose sight and compassion for their fellow man. It is a crime to see children in need being swept under a rug due to political and financial greed. It is a crime that throughout all this time, with full support, MTT could have been fully developed to treat diseases such as muscular dystrophy, cancer, Type II diabetes and heart failure, but it was not. MTT technological development has been hampered for at least two decades. The arbitrary and capricious behavior, the lack of due process, and the abuse of entrusted authority exhibited by FDA operations constitute a crime against humanity.

\section{References}

[1] Law, P.K., Bertorini, T., Goodwin, T.G., et al. (1990) Dystrophin Production Induced by Myoblast Transfer Therapy in Duchenne Muscular Dystrophy. The Lancet, 336, 114-115. https://doi.org/10.1016/0140-6736(90)91628-N

[2] Law, P.K., Goodwin, T.G., Fang, Q., et al. (1997) First Human Myoblast Transfer Therapy Continues to Show Dystrophin after 6 Years. Cell Transplant, 6, 95-100.

[3] Law, P.K. (1995) Methods for Human Myoblast Culture and Transplantation. In: Ricordi, C., Ed., Methods in Cell Transplantation, R.G. Landes, Austin, TX, 707-735.

[4] Law, P.K., Li, H., Chen, M., Fang, Q. and Goodwin, T. (1994) Myoblast Injection Method Regulates Cell Distribution and Fusion. Transplantation Proceedings, 26, 3417-3418. 
[5] Law, P.K. (1992) Myoblast Transplantation. Science, 257, 1329. https://doi.org/10.1126/science.1529326

[6] Law, P.K. (1993) Myoblast Transfer Therapy. Lancet, 341, 247. https://doi.org/10.1016/0140-6736(93)90115-W

[7] Law, P.K., Goodwin, T.G., Fang, Q., et al. (1992) Feasibility, Safety, and Efficacy of Myoblast Transfer Therapy on Duchenne Muscular Dystrophy Boys. Cell Transplant, 1, 235-244. https://doi.org/10.1177/0963689792001002-305

[8] Law, P.K., Goodwin, T.G., Fang, Q., et al. (1991) Pioneering Development of Myoblast Transfer Therapy. In: Angelini, C., Darrieli, G.A. and Fontanan, D., Eds., Muscular Dystrophy Research, Elsevier Science Inc., New York, 109-116.

[9] Law, P.K., Goodwin, T.G., Fang, Q., et al. (1991) Long-Term Improvement in Muscle Function, Structure and Biochemistry Following Myoblast Transfer in DMD. Acta Cardiomiologica, 1, 281-301.

[10] Law, P.K., Goodwin, T.G., Fang, Q., et al. (1993) Cell Transplantation as an Experimental Treatment for Duchenne Muscular Dystrophy. Cell Transplant, 2, 485-505. https://doi.org/10.1177/096368979300200607

[11] Law, P.K., Goodwin, T.G., Fang, Q., et al. (1998) Myoblast Transfer as a Platform Technology of Gene Therapy. Gene Therapy and Molecular Biology, 1, 345-363.

[12] US Food \& Drug Association (2016) FDA Grants Accelerated Approval to First Drug for Duchenne Muscular Dystrophy.

https://www.fda.gov/newsevents/newsroom/pressannouncements/ucm521263.htm

[13] Perrone, M. (2016) FDA Oks 1st Muscular Dystrophy Drug; Awaits Proof It Works. Associated Press.

https://apnews.com/9c4e469479ea438eb42957ba6ecd4710/fda-tentatively-approvesfirst-drug-muscular-dystrophy

[14] Thomas, K. (2017) Insurers Battle Families over Costly Drug for Fatal Disease. The New York Times.

https://www.nytimes.com/2017/06/22/health/duchenne-muscular-dystrophy-drug-e xondys-51.html

[15] Edlin, M. (2017) Controversy Surrounds Exondys 51 Approval: What to Know. Managed Healthcare Executive.

http://managedhealthcareexecutive.modernmedicine.com/managed-healthcare-exec utive/news/controversy-surrounds-exondys-51-approval-what-know?page $=0,1$

[16] Swaminathan, N. (2016) Precision Medicine May Be Health Care's Next Big Thing, But We Don't Yet Know How to Evaluate Precision Drugs. Quartz. https://qz.com/824150/precision-medicine-may-be-health-cares-next-big-thing-but -we-dont-yet-know-how-to-evaluate-precision-drugs/

[17] Silverman, E. (2016) Behind the Sarepta Drug Approval Was Intense FDA Bickering. STAT.

https://www.statnews.com/pharmalot/2016/09/19/sarepta-fda-duchenne-behind-th e-decision/

[18] Seife, C. (2016) FDA Documents Reveal Depths of Internal Rancor over Drug's Approval Process. Undark. https://undark.org/article/fda-eteplirsen-janet-woodcock/

[19] Adams, B. (2016) FDA New Drugs Director Slams Sarepta Approval as "NOT a Good Model". FierceBiotech.

http://www.fiercebiotech.com/biotech/fda-news-drugs-director-slams-sarepta-saysbiotech-s-approval-not-a-good-model 
[20] Silverman, E. (2016) FDA Official Warns Other Drug Makers Not to Copy Sarepta. STAT.

https://www.statnews.com/pharmalot/2016/10/20/fda-warns-drug-companies-abou t-sarepta/

[21] Carroll, J. (2017) Top FDA Official Accused CDER Chief Woodcock of Appearing Biased, Browbeating Reviewers in Demanding Eteplirsen OK. Endpoint News.

https://endpts.com/top-fda-official-accused-cder-chief-woodcock-of-appearing-bias ed-alienating-reviewers-in-demanding-eteplirsen-ok/

[22] Henriques, C. (2017) FDA's Approval of Duchenne Therapy Exondys 51 Sparks Lawsuit by NYU Professor. Muscular Dystrophy News Today.

https://musculardystrophynews.com/2017/05/30/nyu-professor-files-lawsuit-agains t-fda-for-records-on-duchenne-md-exondys-51-approval/

[23] Mosher, D. (2016) A Top Journalist Is Suing the FDA over Its Alleged Use of a Banned and Secretive Practice to Manipulate the News. Business Insider.

http://www.businessinsider.com/fda-journalist-manipulation-embargoes-2016-9

[24] Stennes, M.L. (1997) The Criminalization of Innovation: FDA Misdirection in the Najarian and Burzynski Cases (1997 Third Year Paper) Harvard Law School. http://nrs.harvard.edu/urn-3:HUL.InstRepos:9453691

[25] Law, P., Weinstein, J., Ben Hain, S., et al. (2000) World's First Human Myoblast Transfer into the Heart. Acta Physiologica Scandinavica, A1-A114.

[26] Law, P.K., Haider, K., Fang, G., et al. (2002) Mechanisms of Myoblast Transfer in Treating Heart Failure. In: Kimchi, A., Ed., Advances in Heart Failure, Medimont, New York, 43-48.

[27] Law, P.K., et al. (2003) Myoblast Genome Therapy and the Regenerative Heart. In: Kipshidze, N. and Serruys, P., Eds., Handbook of Cardiovascular Cell Transplantation, Martin Dunitz, Ltd., London, 241-257.

[28] Haider, K.H., Ye, L., Jiang, S.J., Law, P.K. and Sim, E.K.W. (2003) Myoblast Transplantation for Cardiac Repair using Transient Immunosuppression. Basic and Applied Myology, 13, 45-52.

[29] Law, P.K., Fang, G., Chua, F., Kakuchaya, T. and Bockeria, L.A. (2003) First-in-Man Myoblast Allografts for Heart Degeneration. The International Journal of Medical Implants Devices, 1, 100-155.

[30] Law, P.K., et al. (2008) Delivery of Biologics for Angiogenesis and Myogenesis. In: Nguyen, T., Colombo, A., Hu, D., et al., Eds., Practical Handbook of Advanced Interventional Cardiology, 3rd Edition, Blackwell Futura, Malden, 584-596.

[31] Ma, J.H., Su, L.P., Zhu, J., et al. (2013) Skeletal Myoblast Transplantation on Gene Expression Profiles of Insulin Signaling Pathway and Mitochondrial Biogenesis and Function in Skeletal Muscle. Diabetes Research and Clinical Practice, 102, 43-52.

[32] Law, P.K. (2016) Disease Prevention and Alleviation by Human Myoblast Transplantation. Open Journal of Regenerative Medicine, 5, 25-43.

https://doi.org/10.4236/ojrm.2016.52003

[33] Law, P.K., Song, S.J., Lu, P., et al. (2017) World's First Myoblast Treatment of Human Cancer Found Safe and Efficacious. Open Journal of Regenerative Medicine, 6, 1-16. https://doi.org/10.4236/ojrm.2017.61001 


\section{Attachment 1}

FDA News Release September 19, 2016 (abridged)

FDA grants accelerated approval to first drug for Duchenne muscular dystrophy

The U.S. Food and Drug Administration today approved Exondys 51 (eteplirsen) injection, the first drug approved to treat patients with Duchenne muscular dystrophy (DMD). Exondys 51 is specifically indicated for patients who have a confirmed mutation of the dystrophin gene amenable to exon 51 skipping, which affects about 13 percent of the population with DMD.

The FDA has concluded that the data submitted by the applicant demonstrated an increase in dystrophin production that is reasonably likely to predict clinical benefit in some patients with DMD who have a confirmed mutation of the dystrophin gene amenable to exon 51 skipping. A clinical benefit of Exondys 51, including improved motor function, has not been established.

Under the accelerated approval provisions, the FDA is requiring Sarepta Therapeutics to conduct a clinical trial to confirm the drug's clinical benefit. The required study is designed to assess whether Exondys 51 improves motor function of DMD patients with a confirmed mutation of the dystrophin gene amenable to exon 51 skipping. If the trial fails to verify clinical benefit, the FDA may initiate proceedings to withdraw approval of the drug.

The most common side effects reported by participants taking Exondys 51 in the clinical trials were balance disorder and vomiting.

The FDA granted Exondys 51 fast track designation, which is a designation to facilitate the development and expedite the review of drugs that are intended to treat serious conditions and that demonstrate the potential to address an unmet medical need. It was also granted priority review and orphan drug designation. Priority review status is granted to applications for drugs that, if approved, would be a significant improvement in safety or effectiveness in the treatment of a serious condition. Orphan drug designation provides incentives such as clinical trial tax credits, user fee waiver and eligibility for orphan drug exclusivity to assist and encourage the development of drugs for rare diseases.

The FDA, an agency within the U.S. Department of Health and Human Services, protects the public health by assuring the safety, effectiveness, and security of human and veterinary drugs, vaccines and other biological products for human use, and medical devices. 


\title{
Attachment 2
}

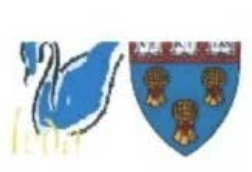

\section{美国哈佛大学法学院教材: FDA 迫害外籍优秀科学家的案例}

http://leda.law.harvard.edu/leda/search/toc.php3?handle=HLS.Library.Leda/stennesml-criminalization innovation_fda

\author{
Search. Home
}

\begin{abstract}
Leda Searchi Results
The Criminalization of Innovation: FDA Misdirection in the Najarian and Burzynski Cases (1997 Third Year Paper)

Author(s): Matthew L. Stennes

Subject \& Subject Keywor ds Food and Drug Law "FDA misdirection" "regulation of physician prescribing" "human drugs" "Najarian" "Burzynski"

Najarian and Burzynski seem the perfect examples of the amazing potential of the American medical establishment. Their visionary work in their respective fields should be celebrated as monumental contributions to society. Rather than being lauded by the nation, though, both men have watched their careers and reputations come hurtling to a disastrous end as they faced criminal charges of fraud, embezzlement, and multiple violations of Food and Drug Administration (FDA) laws which threatened to send them each to prison for the rest of their lives.

PDF version (suitable for printing)

mstennes.pdf (complete document)

HTML version (suitable for viewing with web browser)

mstennes.html (complete document)

Rich Text Format version (suitable for use with word processor)

mstennes. Itf (complete document)

ZIP'ped version (suitable for downloading)

HLS.Library.Leda/stennesml-criminalization innovation fda

Depositors authorize the Legal Information Institute to retain in perpetuity a digital copy of their scholarship and to provide,

without charge, individual users of LEDA with the ability to view or print copies of a LEDA document for private, non-commercial use. Authors retain all other rights, including the rights of subsequent publication.
\end{abstract}

Search Home 